\title{
A vaginal foreign body presenting as vesico-vaginal fistulae in a pre-pubertal girl: A case report and review of the literature
}

\author{
Manupriya Sharma ${ }^{1}$, Mukesh Surya $^{2}$, Raj Kumar Sharma ${ }^{3}$, Anjali Soni ${ }^{2}$ and Chanderdeep Sharma ${ }^{2 *}$ \\ *Correspondence: cdsharma2006@gmail.com

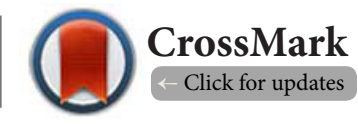 \\ 'Department of Pathology, Dr. Rajendra Prasad Government Medical College, Kangra, India. \\ ${ }^{2}$ Department of Obstetrics and Gynecology, Dr. Rajendra Prasad Government Medical College, Kangra, India. \\ ${ }^{3}$ Department of Surgery, Dr. Rajendra Prasad Government Medical College, Kangra, India.
}

\begin{abstract}
Background: A neglected foreign body in a vagina leading to vesico-vaginal fistulae in young girls is a very rare presentation. As such, it poses significant therapeutic challenges in its management.

Case presentation: A 10-year old pre-pubertal girl presented with malodorous vaginal discharge and continuous dribbling of urine per vaginum. Two separate stones, one each in the vagina and the urinary bladder, with concomitant vesico-vaginal fistulae (VVF) were diagnosed. The history of a foreign body (the cap of a nail paint bottle) inserted into the vagina, while playing, about two years back was elicited. She underwent abdomino-vaginal repair with satisfactory outcome.

Conclusion: Vaginal foreign bodies leading to stone formation and subsequent VVF are a rare presentation. Till date 12 such cases have been reported. This case is being reported to highlight this rare cause of VVF in young girls and to develop consensus regarding its management. The procedure of management here involved first removal of the vaginal foreign body and then prolonged catheterization followed by subsequent repair of VVF after 6-8 weeks. However, individualization of such cases may be required depending upon specific characteristics (e.g., large size in index case).
\end{abstract}

Keywords: Vesico-vaginal fistulae, foreign body vagina, pre-pubertal girl

\section{Introduction}

A variety of foreign bodies such as an aerosol cap, the cap of an eye brow pencil, a stone, a hair spray cap, a toy, a plastic splinter, a bottle cap or a cylindrical tin counter etc., has been extruded from the vagina of young pre-pubertal girls [1]. Such vaginal foreign bodies can lead to malodorous vaginal discharge and vaginal bleeding [2]. As such, continuous urinary/watery leakage, recurrent cystitis, persistent odor, skin infection or irritation or perennial dermatitis etc. may be suggestive of associated vesico-vaginal fistulae (VVF). To the best of our knowledge 12 such cases have been reported till date (Table 1) [2-12]. However, we hereby report a case of self inserted vaginal foreign body (the cap of a nail-paint bottle) leading to stone formation in the vagina and urinary bladder (UB) along with VVF.

\section{Case presentation}

A 10-year old pre-pubertal girl presented to the outpatient department. She had a history of malodorous vaginal discharge for one year and continuous dribbling of urine for the last six months. She declined any history of sexual abuse. There was no history of any previous gynecological surgery or trauma or radiation therapy or any pelvic pathology. On further questioning in detail she admitted that around two years back she had, while playing, inserted the cap of a nail-paint bottle into her vagina. On gentle external examination a stone was visible inside the introitus. It was reaching well beyond the hymen up to external vaginal orifice and urine was seen dribbling just anterior to it (as shown in Figures $\mathbf{1} \mathbf{a}$ and $\mathbf{1} \mathbf{b}$ ).

Chronic vulvar dermatitis because of chronic irritation of vulva caused by continuous dribbling of urine was also seen. An attempt was made to catheterize the urinary bladder but it failed (even with urinary catheter of the smallest size). Plain pelvic radiography revealed two separate stones (as shown in Figure 1). On pelvic ultrasound examination one stone was confirmed in 
Table 1. Vesico-vaginal fistulas associated with foreign bodies in vagina (reported till date).

\begin{tabular}{lllll}
\hline Name of author & $\begin{array}{l}\text { Age } \\
\text { (in years) }\end{array}$ & Year & Foreign body & Surgical approach \\
\hline Juozas Vilimas BS [2] & $13,17,17^{\star}$ & 2015 & Aerosol Cap & Vaginal \\
Evans JM [3] & 22 & 2012 & Bottle Cap & Vaginal \\
Siddiqui NY [4] & 16 & 2007 & Plastic Cup & Abdomino-vaginal \\
Hirai K [5] & 14 & 2005 & Hair spray cap & Abdomino-vaginal \\
Biswas A [6] & 15 & 2002 & Metallic Cup & Vaginal \\
Fourie [7] & 16 & 2001 & Aerosol Cap & Abdominal \\
Arikan N [8] & 18 & 2000 & Aerosol Cap & Abdominal \\
Dalela [9] & 13 & 1994 & Cylindrical tin & Abdomino-vaginal \\
Unda Urzaiz M [10] & 8 & 1989 & Toy & Abdominal \\
Methfessel HD [11] & 18 & 1987 & Plastic splinter & Vaginal \\
\hline
\end{tabular}

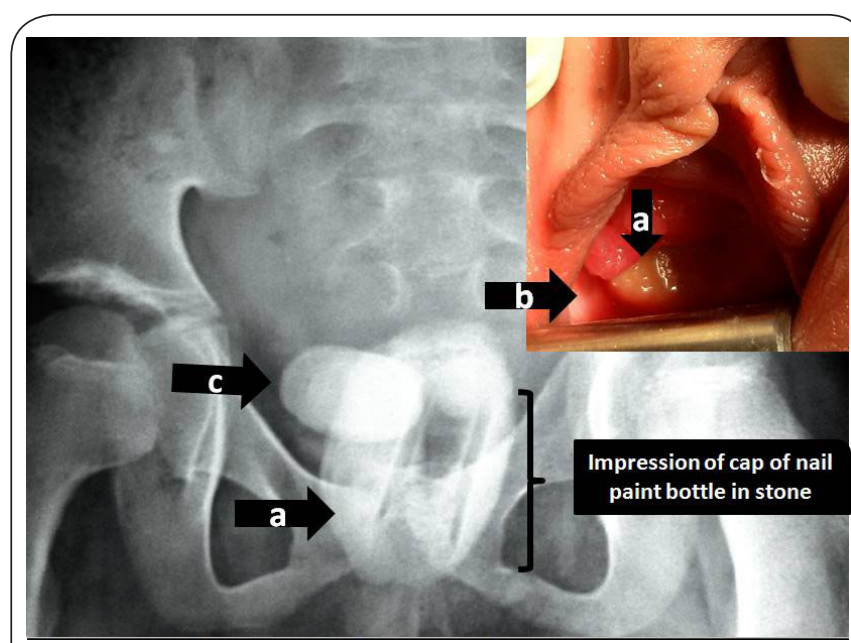

Figure 1. Plain X ray of a young girl with two stones in situ. (a). Stone in vagina encased around cap of nail paint bottle (inset; vaginal stone seen externally in examination under anesthesia). (b). Urine seen dribbling anterior to stone on external examination (c). Second stone in urinary bladder due to obstruction of bladder neck by vaginal stone.

the vagina and another in the urinary bladder. The opinion of the urologist was sought and a plan was made for surgical removal of the vaginal stone. This was to be followed by prolonged UB drainage (6-8 weeks) and subsequent removal of the bladder stone and finally the repair of VVF vaginally. Examination under general anesthesia was made. A large vaginal stone ( $7 * 4$ centimeter) was found completely obstructing the urethra (even reaching up to hymen, as shown in Figure 1 \{inset\}). Any attempt to break this stone was fraught with danger of extensive vaginal and urethral tears. The parents of the patient refused for vaginal exploration/episiotomy for the removal of vaginal stone. They feared subsequent allegations of promiscuous sexual behavior leading to marital discord. So the decision for a combined approach (abdominal and vaginal; without any vaginal incision/episiotomy) was taken. After abdominal incision cystotomy was done and the bladder stone was removed ( $4 * 2 \mathrm{~cm}$ size) \{as shown in Figure 2 \}. Due

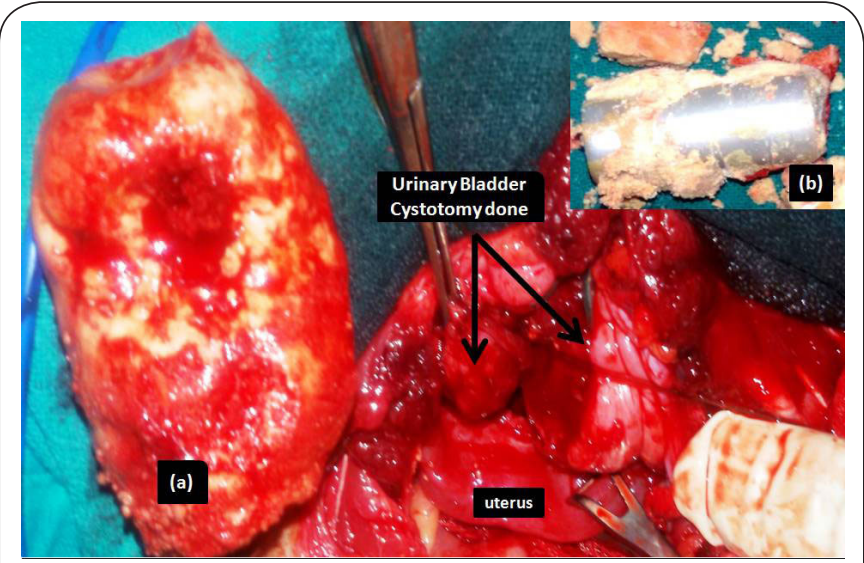

Figure 2. Intra-operative image of cystotomy to remove both stones and repair VVF.

(a). Vaginal stone removed encased around cap of nail paint bottle. (b). Cap of nail paint bottle after breaking vaginal stone.

to very large size of the vaginal stone ( $7 * 4$ centimeters) and apprehensions of the parents regarding vaginal incision, it was impossible to manipulate the vaginal stone abdominally and to remove that subsequently vaginally. So the urinary bladder was dissected from the anterior of the uterus. An incision was given in the anterior vaginal wall and the vaginal stone was also retrieved abdominally (as shown in Figure 2a). Subsequently was made the vaginal wall repair to be followed by repair of vesico-vaginal fistulae and closure of cystotomy. Both supra-pubic catheter and per-uretheral folley's catheter were kept for continuous drainage of UB for about two weeks. Supra-pubic catheter was removed after two weeks. The patient was dry subsequently, and chronic vulvar dermatitis got resolved spontaneously. She was discharged two weeks post-operatively in healthy condition and is on regular follow up. Psychological consultation was also recommended.

\section{Discussion}

A foreign body in the vagina of a pre-pubertal girl and that too leading to VVF is a very rare occurrence. As such, this is 
an important diagnosis, especially while considering the tender age of the patient with many potentially debilitating complications like persistent vaginal discharge, vesico-vaginal fistulae (VVF) and even recto-vaginal fistulae. This rare clinical scenario gets further complicated because of the lack of any definite management guidelines.

Vaginal foreign bodies in pre-pubertal children can be due to sexual abuse and/or self sexual exploration or gratification [12]. Further, an irritation/itching in the genital region may predispose a young child to scratch the genitalia with any foreign body that sometimes may be left inside the vagina inadverdently [12]. A high index of suspicion for sexual abuse is mandatory in order to identify and manage such cases as the child may be unable to properly elicit the sexual abuse $[2,3]$. In developing countries the lack of sex education in schools and family as well as the social stigma usually associated with gynecological complaints by pre-pubertal girls can often lead to a delayed reporting of such occurrences, as was indeed to be seen in the index case.

Though the patient had debilitating symptoms of continuous dribbling of urine vaginally, still the medical help was sought after about six months. The self inserted cap of a nail-paint bottle might have served as a nidus for the deposition of vaginal secretions on this foreign body leading to the formation of a vaginal stone. Further, as this vaginal stone increased in size, it might have led to the pressure of a kind on the urethra and urinary bladder resulting in urinary stasis. This stasis of urine could have resulted in the formation of stone in the UB and consequent constant irritation in the UB might have led to VVF. Fistulas have usually been reported to develop within one to five weeks of a foreign body insertion [13]. Our case is unique in the sense that the presence of a foreign body in the vagina was neglected for almost two years. This led to the formation of a massive secondary vaginal stone $(7 * 4$ centimeters) that occupied almost whole of the vagina. So far only one such case has been reported and that too was in 1980 [14]. Besides, this patient poses a significant dilemma regarding the therapeutic management. Various management options considered for this patient were:

1. Minimal invasive techniques e.g., endoscopic removal of stone by use of hysteroscopy

2. Vaginal removal of stone (either by morcellation or after episiotomy incision)

3. Combined abdomino-vaginal approach (abdominal manipulation with subsequent abdominal or vaginal removal).

As clearly shown in the inset in Figure 1, even though the tip of the stone was visible up to hymen, the main body of the stone was virtually occupying almost whole of the vagina since it was not possible to insert even the smallest sized catheter per urethra. Hysteroscopic removal of the stone was not possible because of the very large size of the stone that virtually occupied almost whole of the vagina. The method of endoscopic lithotripsy or nephroscopic removal of the bladder stone was not practically feasible till the vaginal stone was removed (as the vaginal stone was the inciting event for the UB stone).

In the absence of a planned vaginal incision/episiotomy, any vaginal exploration would have resulted in extensive traumatic lacerations to the vagina or urethra. In the face of a detailed informed consent, the parents of the girl refused to give their consent for any vaginal surgery (incision/episiotomy). They were afraid of any future marital discord along with allegations of promiscuous sexual activity by the girl's would be husband (due to any externally visible vaginal scar). Even an extensive counseling could not change their views regarding these things.

In our opinion, the best approach would have been to remove the vaginal stone after giving episiotomy (morcellation too if required), to allow continuous UB drainage (6-8 weeks) and to attempt VVF repair at a later stage. However, the refusal of the girl's parents for vaginal incision/episiotomy and large size of the vaginal stone were major impediments in this plan. Hence a radical approach of abdomino-vaginal manipulation as well as the removal of stone was adopted. It was further decided to complete the surgery in one setting (i.e., to remove the UB stone and repair the VVF at the same setting) so as not to predispose this young patient to repeated surgeries.

This case is being reported to familiarize both the gynecologists and the urologists with this extremely rare as well as a very debilitating presentation. This is a very rare and unique clinical presentation. Due to the social stigma associated with vaginal discharge (especially in case of young girls in the developing countries) the patient approached the hospital very late and this led to a phenomenal enlargement of the vaginal stone. In addition to that, orthodox societal norms regarding sexual practices (still prevalent in many developing countries) necessitated a more radical approach (abdomino-vaginal) for the management of this case. Quite evidently, this case also stresses the need for proper sex education in the schools as well as families, especially in the developing countries.

\section{Competing interests}

The authors declare that they have no competing interests.

\section{Publication history}

Editor: Babatunde Abiodun Gbolade, St. James's University Hospita, UK. EIC: Christos lavazzo, Royal Surrey County Hospital, UK.

Received: 02-May-2016 Final Revised: 08-Jul-2016

Accepted: 25-Jul-2016 Published: 01-Aug-2016

\section{References}

1. Shiryazdi SM, Heiranizadeh $\mathrm{N}$ and Soltani HR. Rectorrhagia and vaginal discharge caused by a vaginal foreign body--a case report and review of literature. J Pediatr Adolesc Gynecol. 2013; 26:e73-5. I Article I PubMed

2. Vilimas J, Baseviciene I, Kilda A, Puzinas A and Verkauskas G. Vesicovaginal Fistula in Adolescent Girls: Incidence and Management. J Pediatr Adolesc Gynecol. 2015; 28:e185-7. I Article I PubMed

3. Evans JM, South MM and Karram MM. Vesicovaginal fistula due to 
Sharma et al., Gynecology 2016,

http://www.hoajonline.com/journals/pdf/2052-6210-4-2.pdf

doi: $10.7243 / 2052-6210-4-2$

remote history of vaginal foreign body. Female Pelvic Med Reconstr Surg. 2012; 18:374-5. | Article | PubMed

4. Siddiqui NY and Paraiso MF. Vesicovaginal fistula due to an unreported foreign body in an adolescent. J Pediatr Adolesc Gynecol. 2007; 20:2535. | Article | PubMed

5. Hirai K, Kita K, Mikata K, Fujikawa N and Kitami K. [Vesicovaginal fistula associated with a vaginal foreign body: a case report]. Hinyokika Kiyo. 2005; 51:283-6. | Article | PubMed

6. Biswas $A$ and Das $\mathrm{HS}$. An unusual foreign body in the vagina producing vesicovaginal fistula. J Indian Med Assoc. 2002; 100:257, 259. | Article | PubMed

7. Fourie $T$ and Ramphal S. Aerosol caps and vesicovaginal fistulas. Int J Gynaecol Obstet. 2001; 73:275-6. | Article | PubMed

8. Arikan N, Turkolmez K, Aytac S and Gogus O. Vesicovaginal fistula associated with a vaginal foreign body. BJU Int. 2000; 85:375-6. | Article I PubMed

9. Dalela D, Agarwal R and Mishra VK. Giant vaginolith around an unusual foreign body--an uncommon cause of urinary incontinence in a girl. $\mathrm{Br} J$ Urol. 1994; 74:673-4. | Article | PubMed

10. Unda Urzaiz M, Prieto Ugidos N, Iriarte Soldevilla I, de Soto Arranz C and Flores Corral N. [Vesicovaginal fistula in an 8-year-old girl]. Arch Esp Urol. 1989; 42:473-5. I Article I PubMed

11. Methfessel HD. [Rare foreign body fistulas of the female bladder]. $Z$ Urol Nephrol. 1987; 80:545-9. I Article I PubMed

12. Closson FT and Lichenstein R. Vaginal foreign bodies and child sexual abuse: an important consideration. West J Emerg Med. 2013; 14:437-9. | Article | PubMed Abstract | PubMed FullText

13. Singh O, Gupta SS and Mathur RK. Urogenital fistulas in women: 5-year experience at a single center. Urol J. 2010; 7:35-9. I PubMed

14. Jaspers JW, Kuppens SM, van Zundert AA and de Wildt MJ. Vaginal stones in a 5-year-old girl: a novel approach of removal. J Pediatr Adolesc Gynecol. 2010; 23:e23-5. | Article | PubMed

\section{Citation:}

Sharma M, Surya M, Sharma RK, Soni A and Sharma C. A vaginal foreign body presenting as vesico-vaginal fistulae in a pre-pubertal girl: $\mathrm{A}$ case report and review of the literature. Gynecol. 2016; 4:2. http://dx.doi.org/10.7243/2052-6210-4-2 